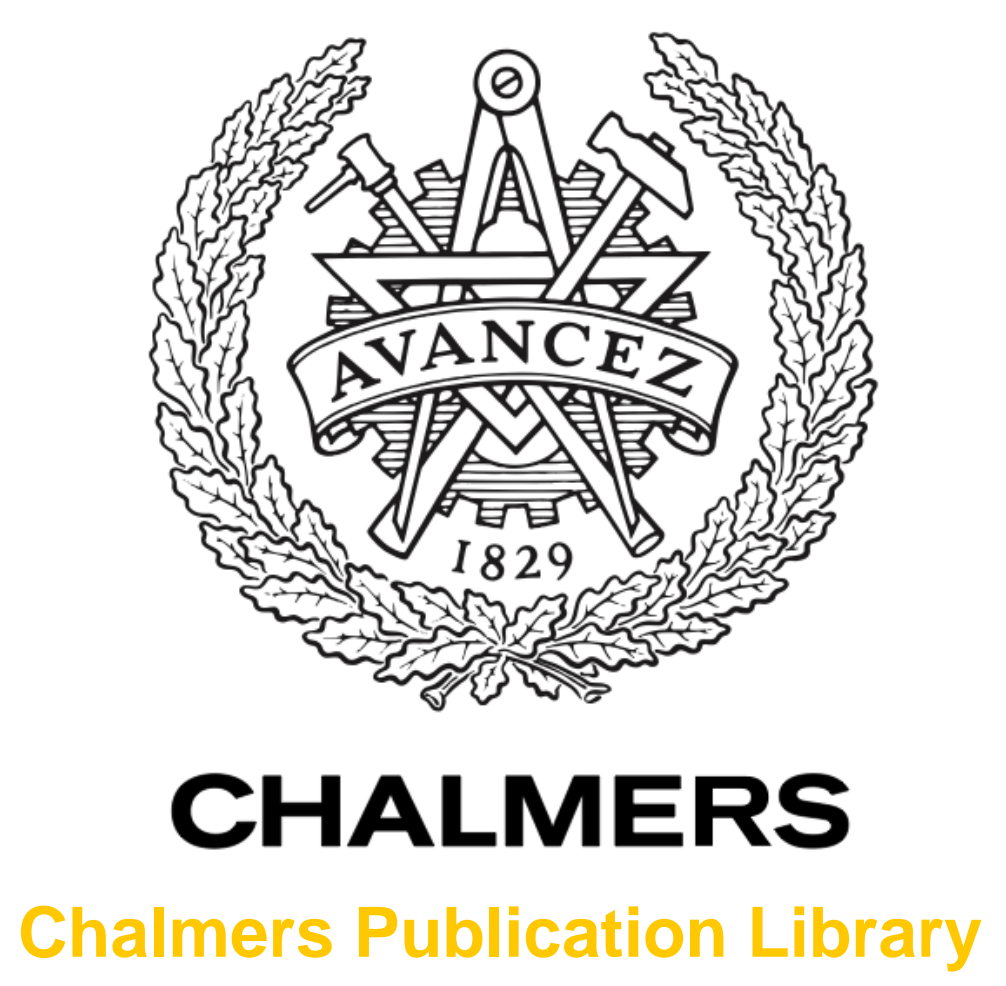

Quad-Mode Antenna for Wide-Scan Sparse Arrays

This document has been downloaded from Chalmers Publication Library $(\mathrm{CPL})$. It is the author's version of a work that was accepted for publication in:

2015 IEEE International Symposium on Antennas and Propagation \& USNC/URSI National Radio Science Meeting

Citation for the published paper:

Prinsloo, D. ; Meyer, P. ; Maaskant, R. et al. (2015) "Quad-Mode Antenna for Wide-Scan Sparse Arrays". 2015 IEEE International Symposium on Antennas and Propagation \& USNC/URSI National Radio Science Meeting pp. 1516-1517.

http://dx.doi.org/10.1109/APS.2015.7305147

Downloaded from: http://publications.lib.chalmers.se/publication/227917

Notice: Changes introduced as a result of publishing processes such as copy-editing and formatting may not be reflected in this document. For a definitive version of this work, please refer to the published source. Please note that access to the published version might require a subscription.

Chalmers Publication Library (CPL) offers the possibility of retrieving research publications produced at Chalmers University of Technology. It covers all types of publications: articles, dissertations, licentiate theses, masters theses, conference papers, reports etc. Since 2006 it is the official tool for Chalmers official publication statistics. To ensure that Chalmers research results are disseminated as widely as possible, an Open Access Policy has been adopted.

The CPL service is administrated and maintained by Chalmers Library. 


\section{Quad-Mode Antenna for Wide-Scan Sparse Arrays}

\author{
D.S. Prinsloo and P. Meyer \\ Dept. Electrical and Electronic Engineering \\ Stellenbosch University \\ Stellenbosch, Western Cape, South Africa \\ email:\{16238087,pmeyer\}@sun.ac.za
}

\author{
R. Maaskant and M.V. Ivashina \\ Dept. Signals and Systems, Antenna Group \\ Chalmers University of Technology \\ Gothenburg, Sweden \\ email:\{rob.maaskant, marianna.ivashina\}@chalmers.se
}

\begin{abstract}
A conical quad-mode antenna excited through four orthogonal transverse electromagnetic modes is presented. The radiation characteristics of each mode are validated through measurements, illustrating the complimentary nature of the four far-field radiation patterns through which near-hemispherical field-of-view coverage can be achieved.
\end{abstract}

\section{INTRODUCTION}

The authors recently proposed the use of multi-mode antennas to extend the Field-of-View (FoV) coverage of phasedarray antenna elements implemented in sparse configurations [1], [2]. These antennas utilize multiple orthogonal Transverse Electromagnetic (TEM) modes to excite integrated, and co-located, dipole and monopole elements through a multiconductor transmission line. In [3], the authors introduce a conical quad-mode antenna and illustrate the improved FoV coverage with respect to gain, sensitivity and polarimetric performance that can be obtained through judicious use of the four available TEM excitation modes.

This paper presents the measured multi-mode response of a conical quad-mode antenna design. The presented results affirm the complimentary nature of the four orthogonal excitation modes that enables the quad-mode antenna to achieve near-hemispherical FoV coverage.

\section{Conical Quad-Mode Antenna Design}

The conical quad-mode antenna design presented in this paper operates at a center frequency of $950 \mathrm{MHz}$ with an operating frequency bandwidth of approximately $35 \%$. As shown in Fig. 1, the antenna comprises two perpendicularly oriented bow-tie antennas printed on a FR-4 substrate positioned above a $2 \mathrm{~mm}$ thick aluminium conical monopole sleeve connected to the ground shield of a quadraxial transmission line at the apex. The conical monopole element extends downward up to a distance $\left(h_{1}\right)$ from the ground plane. To excite the antenna, four coaxial connectors are positioned below the ground plane, where the center conductor of each connector is connected to one of the brass inner conductors of the air-core quadraxial feed - each with a diameter of $5 \mathrm{~mm}$. As shown in Fig. 1(b), the four inner conductors of the feed are each terminated in one of the bow-tie arms. Table I summarizes the design dimensions indicated in Fig. 1.

To illustrate the radiation characteristics of the quad-mode antenna consider the simulated field distributions of the four

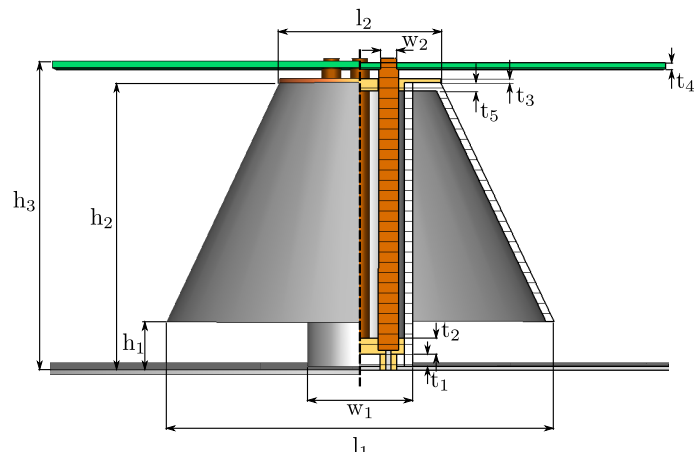

(a)

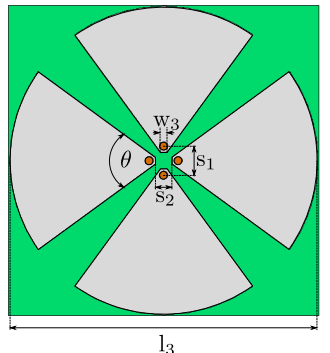

(b)

Fig. 1. Conical quad-mode antenna design (a) side view showing inner conductor of quadraxial feed (b) top view of printed bow-tie antennas.

TABLE I

CONICAL QUAD-MODE ANTENNA DESIGN PARAMETERS

\begin{tabular}{c|c|l} 
Parameter & Value $[\mathrm{mm}]$ & Description \\
\hline $\mathrm{w}_{1}$ & 26.15 & Ground shield outer diameter \\
$\mathrm{w}_{2}$ & 4 & Reduced inner conductor diameter \\
$\mathrm{w}_{3}$ & 3.3 & Bow-tie inner edge width \\
$\mathrm{t}_{1}$ & 3 & Aluminium feed short thickness \\
$\mathrm{t}_{2}$ & 4 & Bottom Teflon spacer thickness \\
$\mathrm{t}_{3}$ & 1 & Top Teflon spacer extrusion above cone \\
$\mathrm{t}_{4}$ & 1.6 & FR-4 substrate \\
$\mathrm{t}_{5}$ & 2 & Top Teflon spacer feed extrusion depth \\
$\mathrm{l}_{1}$ & 96 & Conical monopole bottom length \\
$\mathrm{l}_{2}$ & 40 & Conical monopole top length \\
$\mathrm{l}_{3}$ & 150 & Bow-tie dipole length \\
$\mathrm{h}_{1}$ & 11 & Conical monopole - ground plane separation \\
$\mathrm{h}_{2}$ & 70 & Quadraxial feed height \\
$\mathrm{h}_{3}$ & 75 & Dipole height \\
$\mathrm{s}_{1}$ & 14.15 & SMA feed center separation \\
$\mathrm{s}_{2}$ & 8 & Bow-tie arm inner edge separation \\
$\theta$ & 72 & Bow-tie arm flare angle
\end{tabular}




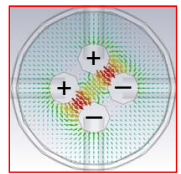

(a)

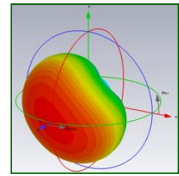

(e)

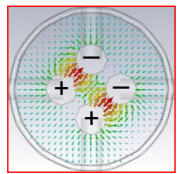

(b)

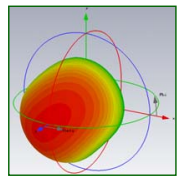

(f)

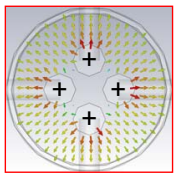

(c)

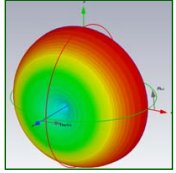

(g)

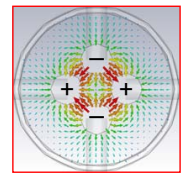

(d)

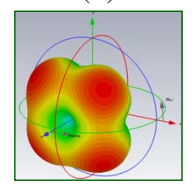

(h)
Fig. 2. Field distribution of port excitation modes (a) $\mathrm{MM}_{1}$, (b) $\mathrm{MM}_{2}$, (c) $\mathrm{MM}_{3}$, (d) $\mathrm{MM}_{4}$ and corresponding radiated far-field patterns of modes (e) $\mathrm{MM}_{1}$, (f) $\mathrm{MM}_{2}$, (g) $\mathrm{MM}_{3}$, and (h) $\mathrm{MM}_{4}$.

orthogonal TEM port excitation modes with their corresponding radiated far-field patterns [c.f. Fig. 2], as simulated in CST Microwave Studio over an infinite ground plane. As shown in Fig. 2, excitation modes $\mathrm{MM}_{1}$ and $\mathrm{MM}_{2}$ result in two orthogonal dipole-over-ground far-field patterns, mode $\mathrm{MM}_{3}$ radiates in a typical monopole fashion and excitation mode $\mathrm{MM}_{4}$ radiates power diagonal to the orientation of the bowtie antennas. It is noted from Figs. 2(e)-(h) that, collectively, these four excitation modes allow for a hemispherical scanrange.

\section{MEASURED RESPONSE}

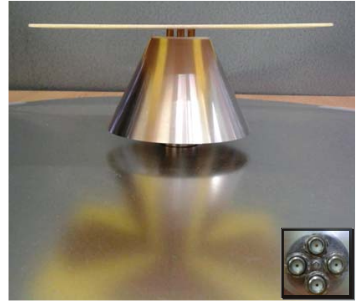

(a)

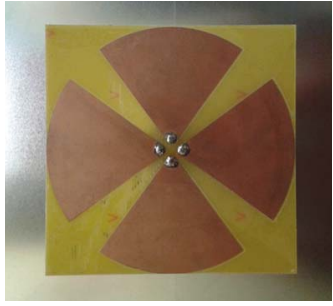

(b)
Fig. 3. Manufactured quad-mode antenna (a) side view showing four SMA connectors (b) top view of printed bow-tie antennas.

To verify the simulated response of the quad-mode antenna, the manufactured design is placed on a circular ground plane with a diameter of $450 \mathrm{~mm}$. Figure 3 shows the measured conical quad-mode antenna design as well as the four coaxial connectors through which the antenna is excited.

As reported in [4], the multi-mode response of the quadmode antenna can be obtained from conventional SingleEnded (SE) radiated far-field pattern measurements where each SE far-field is measured by individually exciting each port with the remaining three ports terminated in a matched load. Figure 4 compares the multi-mode co-polar gain, transformed from SE far-field measurements, to the co-polar gain simulated in CST using the multi-mode port excitations illustrated in Figs. 2(a)-(d). Given the symmetrical design, only the $\phi=0^{\circ}$ plane measurements are shown.

The measurements in Fig. 4 are seen to be in close correspondence to the radiation characteristics of the four

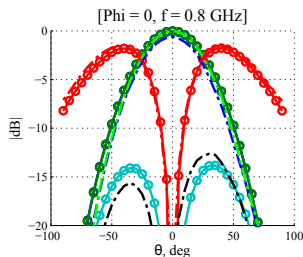

(a)

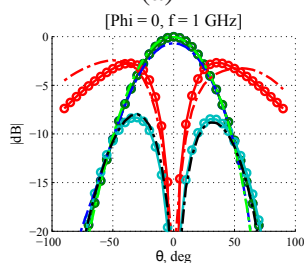

(c)

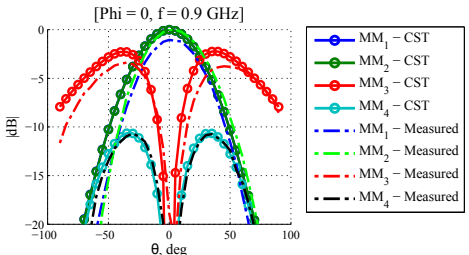

(b)

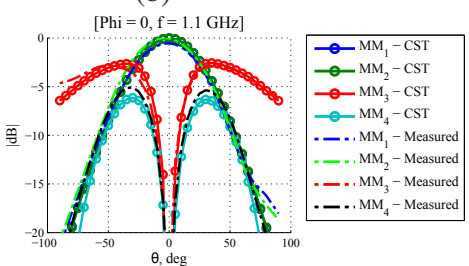

(d)
Fig. 4. Measured and simulated co-polar gain (normalized) in the $\phi=0^{\circ}$ plane at (a) $800 \mathrm{MHz}$, (b) $900 \mathrm{MHz}$, (c) $1 \mathrm{GHz}$, and (d) $1.1 \mathrm{GHz}$.

orthogonal excitation modes observed in the simulated results illustrated in Fig. 2. Furthermore, the measurements are seen to agree with the co-polar gain of each mode simulated in CST over the finite circular ground plane. Modes $\mathbf{M M}_{1}$ and $\mathrm{MM}_{2}$ are seen to radiate dipole-over-ground patterns across the frequency band with mode $\mathrm{MM}_{3}$ radiating in a typical monopole fashion. Note that the lower measured gain of mode $\mathrm{MM}_{4}$ can be attributed to the mismatch of this mode observed within the operating frequency band [3].

\section{CONCLUSION}

This paper presents the design of a conical quad-mode antenna for wide scan-range irregular phased array applications. The radiation characteristics of the four orthogonal excitation modes that collectively allow for hemispherical FoV coverage are introduced and validated through measurements.

\section{ACKNOWLEDGEMENT}

This research was supported by a MCA International Research Staff Exchange Scheme Fellowship within the European FP7 Programme, contract no. 612599. The authors would also like to acknowledge SKA SA, the South African Research Chairs Initiative of the DST, the NRF, as well as the Swedish VR and VINNOVA agencies for funding this work.

\section{REFERENCES}

[1] D. Prinsloo, P. Meyer, M. Ivashina, and R. Maaskant, "A quad-mode antenna for accurate polarimetric measurements over an ultra-wide fieldof-view," in 8th European Conf. on Antennas and Propag. (EuCAP), April 2014, pp. 3794-3797.

[2] D. Prinsloo, R. Maaskant, M. Ivashina, and P. Meyer, "Mixed-mode sensitivity analysis of a combined differential and common mode active receiving antenna providing near-hemispherical field-of-view coverage," IEEE Trans. Antennas Propag., vol. 62, no. 8, pp. 3951-3961, Aug. 2014.

[3] D. Prinsloo, M. Ivashina, R. Maaskant, and P. Meyer, "Beamforming strategies for active multi-mode antennas: Maximum gain, signal-to-noise ratio, and polarization discrimination," in Int. Conf. on Electromagnetics in Advanced Applicat. (ICEAA), Sep. 2014, pp. 507-510.

[4] P. Meyer and D. Prinsloo, "Generalized mixed-mode scattering parameters and antenna far-field conversions," IEEE Trans. Antennas Propag., submitted for publication. 